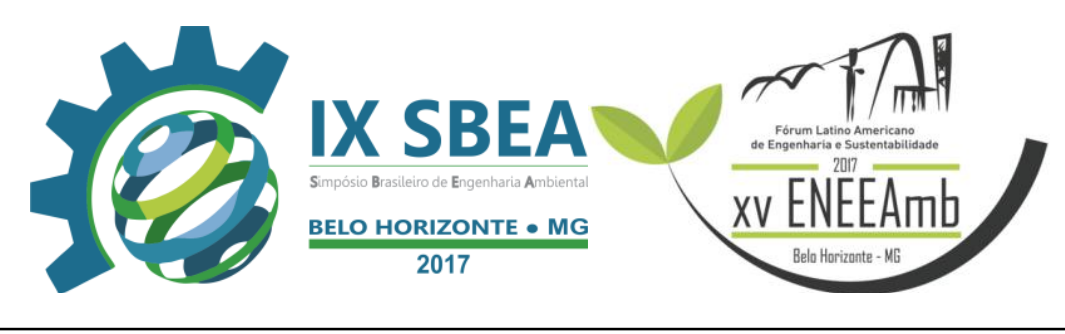

ÁREA TEMÁTICA: RECURSOS HÍDRICOS E SANEAMENTO

\title{
LODOS DE INDÚSTRIAS DE LATICÍNIOS: REQUISITOS PARA DISPOSIÇÃO NO SOLO
}

Ozanan de Almeida Dias - ozanandias@gmail.com

Faculdades Santo Agostinho - FASA de Montes Claros - MG

Fernanda Silva Aguiar - fernandaaguiarmel@ hotmail.com

Faculdades Santo Agostinho - FASA de Montes Claros - MG

Thainá de Paula Cacique e Silva - thainakacique@ hotmail.com

Faculdades Santo Agostinho - FASA de Montes Claros - MG

Vitor Hugo Silva Veloso - vitordakar123@ gmail.com

Faculdades Santo Agostinho - FASA de Montes Claros - MG

Paulo Adriano Catulé Lima - pauloadrianocatule@gmail.com

Faculdades Santo Agostinho - FASA de Montes Claros - MG 


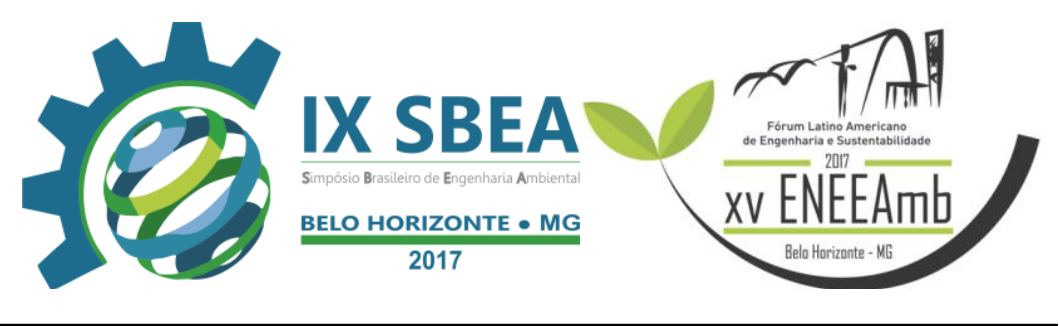

\section{RESUMO}

Entre as alternativas de reutilização do lodo de esgoto, tem-se difundido a prática de disposição desse resíduo em solo agrícola e florestal, como fonte de nutrientes e condicionador do solo. Apesar disso, o lodo de esgoto pode apresentar em sua composição diversos poluentes, como metais pesados, compostos orgânicos persistentes e organismos patogênicos. Diante disso, objetivou-se nesse trabalho caracterizar um composto orgânico que é disposto em solo de plantios florestais de eucaliptos. Sendo esse composto constituído por cinzas, serragens e predominantemente por lodos de efluentes de duas indústrias de laticínios. Para o desenvolvimento do trabalho, realizaram-se análises laboratoriais de amostras do composto orgânico para caracterizá-lo quanto às substâncias inorgânicas, indicadores microbiológicos e estabilidade. A avaliação do lodo não identificou nenhuma restrição quanto às substâncias inorgânicas, pois os resultados das análises não excederam os limites fixados na legislação. Já os resultados dos agentes patogênicos, somente no ano de 2009 o composto orgânico atendeu a resolução CONAMA n 375/2006, tendo em vista a conformidade com as exigências do lodo tipo B. Apenas no ano de 2011 o composto orgânico apresentou-se como não estável, não propiciando o seu uso em solo florestal. Diante dos resultados, pode-se concluir que o composto orgânico avaliado não possui restrições quanto às substâncias inorgânicas, contudo, não atende os requisitos microbiológicos e de estabilidade fixados na Resolução CONAMA n 375/2006.

Palavras-chave: lodo de esgoto, patógenos, estabilidade, disposição no solo.

\section{INTRODUÇÃO/OBJETIVO}

O setor de saneamento ambiental enfrenta atualmente dificuldades crescentes com o gerenciamento dos resíduos gerados nas Estações de Tratamento de Esgotos ETE's (MARQUES et al., 2007). Entre esses resíduos, os lodos produzidos nas ETE's destacam-se como o mais crítico em função da grande quantidade gerada e dos custos elevados de gerenciamento, principalmente no que diz respeito ao processamento e disposição final (PEGORINI \& ANDREOLI, 2006).

Vieira (2015) ressalta uma tendência do aumento considerável da quantidade de lodo de esgoto que requer processamento, sobretudo, em virtude do crescimento 


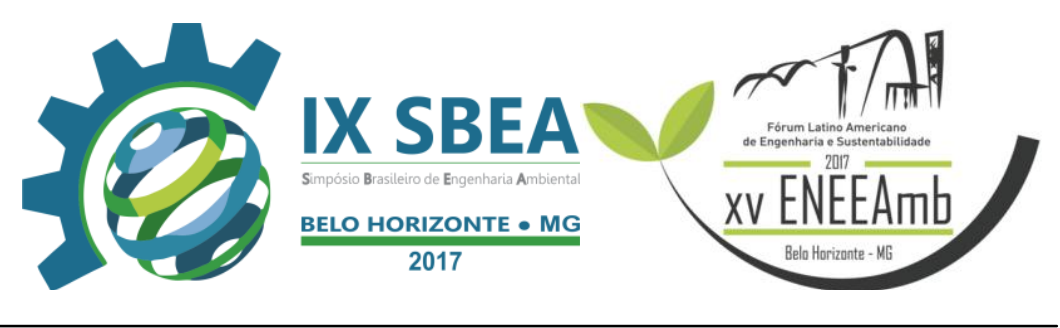

populacional e industrial. Nesse sentido, as indústrias empregam grandes esforços para promover a destinação final dos lodos, devido à importância e complexidade dessa atividade, pois ela extrapola os limites das estações de tratamento (RIBEIRO et al., 2012). Essa crescente produção de lodo tem levado ao desenvolvimento de novas alternativas de disposição final, as quais atendam aos requisitos ambientais e ao mesmo tempo sejam economicamente viáveis.

Dentre essas alternativas de disposição dos lodos de esgoto, tem-se a reutilização desse resíduo em solo agrícola e florestal (LOPES et al., 2005). O lodo caracteriza-se como fonte de nitrogênio, fósforo e de outros nutrientes essenciais e benéficos às plantas, além disso, apresenta variada umidade e elevado teor de matéria orgânica (RIGO et al., 2014). Apesar das vantagens, o lodo de esgoto apresenta em sua composição diversos poluentes, como metais pesados, compostos orgânicos persistentes e organismos patogênicos ao homem (BETTIOL \& CAMARGO, 2006). A fim de que o lodo de esgoto esteja apropriado para utilização agrícola, devem-se considerar as regulamentações legais que estabelecem os critérios e procedimentos para a sua aplicação no solo.

No Brasil, a Resolução CONAMA n 375/2006 define os critérios e procedimentos para o uso agrícola de lodos gerados em estações de tratamento de esgoto sanitário e seus produtos derivados (BRASIL, 2006). Dessa forma, garantindo maior segurança a qualidade do meio ambiente e segurança às populações quanto à saúde pública. Nesse sentido, as estações que tratam conjuntamente efluentes industriais e sanitários, mesmo que esse último seja em menor proporção, o lodo gerado deverá atender as diretrizes da resolução supracitada no que se refere à disposição em solo agrícola.

Diante do exposto, o presente trabalho tem como objetivo caracterizar, quanto às substâncias inorgânicas, indicadores microbiológicos e estabilidade, um composto orgânico que atualmente é disposto em solo de plantios florestais de eucaliptos. Sendo esse composto constituído por cinzas, serragens e predominantemente por lodos provenientes das estações de tratamento de efluentes industriais e sanitários de duas empresas de laticínios. Além disso, através dessa caracterização, pretende-se avaliar a 


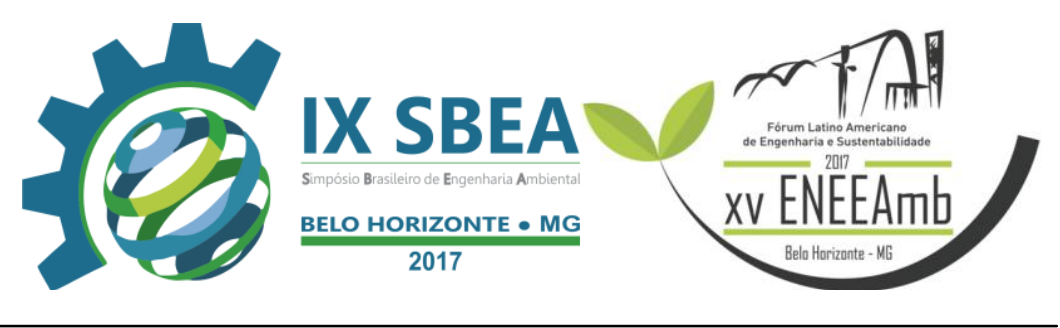

conformidade do composto orgânico com as diretrizes da Resolução CONAMA $n^{\circ}$ $375 / 2006$.

\section{METODOLOGIA}

O composto orgânico caracterizado nesse estudo é proveniente da mistura de lodos gerados em duas ETE's mais as cinzas e serragens descartadas de uma caldeira. Atualmente esse composto rico em matéria orgânica e em nutrientes é utilizado na fertilização de 40,00 hectares de silvicultura de eucalipto. Os resíduos que constituem o composto orgânico são originários de duas indústrias de laticínios, sendo uma delas inserida em Montes Claros (Unidade A) e a outra na cidade de Teófilo Otoni (Unidade B), ambas no estado de Minas Gerais.

Essas indústrias exercem atividades correlatas aos lacticínios, tendo como produto final o leite pré-condensado e condensado. Em ambos os empreendimentos, todo o efluente líquido gerado no processo produtivo, correspondente a $99 \%$ industrial e a $1 \%$ doméstico e sanitário, são encaminhados para as suas respectivas ETE's. O sistema de tratamento da Unidade A consiste em um sistema biológico aeróbio de tratamento através de lodos ativados em fluxo contínuo, com aeração prolongada por meio de aeradores de superfície. Da mesma forma, a Unidade B emprega o tratamento por lodos ativados em fluxo contínuo, contudo, a aeração prolongada ocorre pela utilização de ar difuso.

No processo do tratamento dos efluentes, são gerados nas ETE's em média 1.000,6 t/ano de lodo na Unidade A e 20,8 t/ano de lodo na Unidade B, correspondendo a $94,6 \%$ do volume total do composto orgânico. Além disso, é acrescida nesse composto, a média de 58,15 t/ano de cinzas mais serragens provenientes da caldeira operada na Unidade A. Os lodos das ETE's, assim como o composto orgânico que é disposto no solo do plantio florestal, não sofrem nenhum processo de redução de patógenos.

No que tange ao desenvolvimento do trabalho, realizaram-se análises laboratoriais de amostras do composto orgânico para caracterizá-lo quanto às substâncias inorgânicas, indicadores microbiológicos e estabilidade. Para tanto, os parâmetros analisados foram (i) arsênio, bário, cádmio, chumbo, cobre, cromo, 


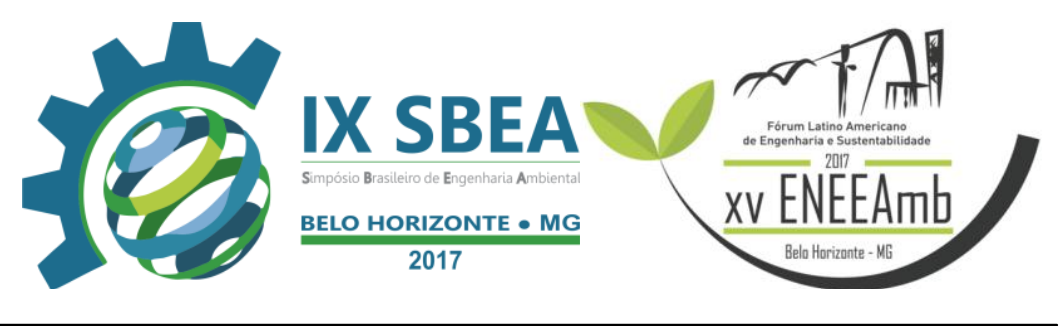

mercúrio, molibdênio, níquel, selênio e zinco; (ii) coliformes termotolerantes, ovos viáveis de helmintos e salmonella; e (iii) sólidos voláteis e sólidos totais. Diante disso, para avaliar a conformidade, no que se refere às questões ambientais, comparou-se os resultados com as diretrizes da Resolução CONAMA n 375/2006, a qual define os critérios e procedimentos para o uso agrícola de lodos gerados em estações de tratamento de esgoto sanitário e seus produtos derivados.

As amostragens ocorreram entre os anos de 2008 a 2011, sendo realizada anualmente, conforme a NBR-10007:2004, a coleta de 01 (uma) amostra compostas originárias de 10 (dez) sub-amostras de iguais quantidades, que foi encaminhada para análise no laboratório Bioagri Ambiental Ltda. em Belo Horizonte (MG). As análises laboratoriais foram realizadas de acordo com a metodologia descrita pela última versão do Standard Methods for the Examination of Water \& Wastewater 22nd 2012 (SMWW), EPA e ABNT (quando aplicável).

\section{RESULTADOS E DISCUSSÃO}

No que diz respeito às substâncias inorgânicas analisadas no composto, os resultados (Tabela 1) não indicaram restrição quanto à aplicação desse resíduo no solo do plantio florestal, uma vez que os parâmetros não excederam os limites estabelecidos na Resolução CONAMA n 375/2006 em nenhuma das análises realizadas. Já era esperado esse resultado em virtude da qualidade dos efluentes líquidos das ETE's, os quais não apresentam valores elevados dessas mesmas substâncias.

Andreoli et al. (2014) ressaltam que a composição do lodo está relacionada às características do efluente e dos processos de tratamento adotado. Portanto, a qualidade do lodo de uma ETE industrial dependerá das peculiaridades da atividade exercida no empreendimento, assim como a composição química dos materiais utilizados na produção, os quais determinarão a qualidade do efluente. Na situação de empresas de laticínios, não são utilizados insumos na produção que possam conferir às águas residuárias a presença elevada de substâncias inorgânicas, como as analisadas no presente estudo.

Observa-se que a maioria dos trabalhos acadêmicos e científicos estão relacionados à avaliação e caracterização de lodos de ETE's municipais ou 


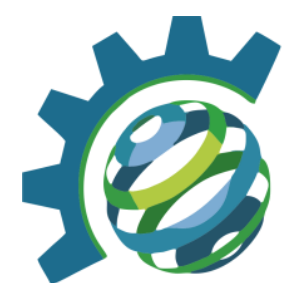

concessionárias de saneamento, que tratam principalmente esgotos sanitários e domésticos. Existem muitos poucos trabalhos que avaliam lodos de ETE's de indústrias, o que dificultou sobre maneira a comparação dos resultados encontrados nessa pesquisa com os de outros autores.

Tabela 1- Resultados analíticos das substâncias inorgânicas presente no composto.

\begin{tabular}{|l|c|c|c|c|c|}
\hline \multirow{2}{*}{ Parâmetros } & \multicolumn{4}{|c|}{ Resultados analíticos (mg/Kg) } & Máximo \\
\cline { 2 - 5 } & 2008 & 2009 & 2010 & 2011 & 375 \\
\hline Arsênio & 0,40 & 1,00 & 2,00 & 1,90 & 41,00 \\
\hline Bário & 2,80 & 76,00 & 108,00 & 624,00 & $1.300,00$ \\
\hline Cádmio & 0,40 & 0,10 & 0,20 & 39,00 & 39,00 \\
\hline Chumbo & 1,00 & 13,00 & 7,80 & 11,00 & 300,00 \\
\hline Cobre & 2,30 & 13,00 & 82,00 & 55,00 & $1.500,00$ \\
\hline Cromo & 1,10 & 24,00 & 16,00 & 71,00 & $1.000,00$ \\
\hline Mercúrio & 0,28 & 0,40 & 0,47 & 0,96 & 17,00 \\
\hline Molibdênio & 0,40 & 1,00 & 2,00 & 2,00 & 50,00 \\
\hline Níquel & 0,50 & 13,00 & 8,20 & 46,00 & 420,00 \\
\hline Selênio & 0,40 & 1,00 & 2,00 & 4,00 & 100,00 \\
\hline Zinco & 24,00 & 56,00 & 268,00 & 75,00 & $2.800,00$ \\
\hline
\end{tabular}

Fonte: Próprios autores.

Dos trabalhos que foram encontrados, estes estão relacionados à avaliação de lodos de ETE's de indústrias químicas. Trannin et al. (2008) ao avaliar o lodo da ETE de uma indústria de fibras e resinas PET (polietileno tereftalato) encontrou valores de substâncias inorgânicas bem abaixo do valor máximo fixado na Resolução CONAMA $\mathrm{n}^{\circ}$ 375/2006. Resultados semelhantes foram obtidos por Behling (2009) na caracterização do lodo da ETE de um empreendimento de produção de borracha sintética e Rosa (2004) ao analisar o lodo da ETE de indústria têxtil.

Quanto aos resultados dos agentes patogênicos (Tabela 2), somente no ano de 2009 o composto orgânico atendeu a resolução CONAMA n ${ }^{\circ}$ 375/2006 quando avaliado conjuntamente os parâmetros, tendo em vista a conformidade com as 


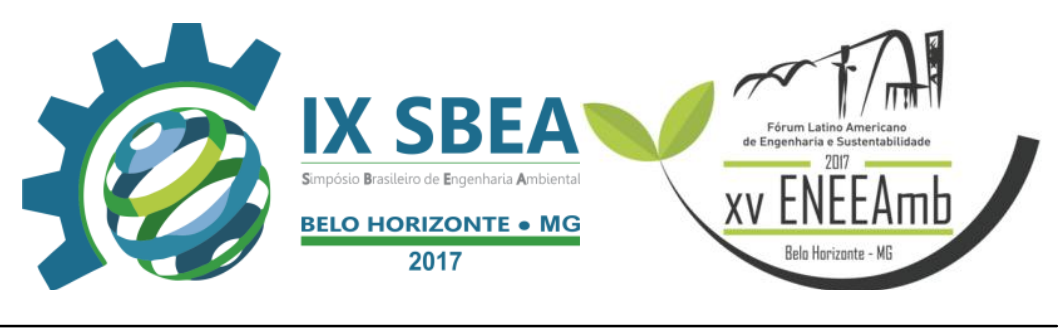

exigências do lodo tipo B. De acordo com Bastos et al. (2009) o lodo tipo B somente podem ser utilizados no cultivo de café, silvicultura, culturas para produção de fibras e óleos, com a aplicação mecanizada, em sulcos ou covas, seguida de incorporação.

Tabela 2 - Resultados analíticos dos agentes patogênicos presentes no composto.

\begin{tabular}{|l|c|c|c|c|c|c|c|}
\hline \multirow{2}{*}{ Parâmetro } & \multicolumn{4}{|c|}{ Resultados analíticos (\% p/p) } & \multicolumn{2}{c|}{ Máximo } \\
& CONAMA 357 \\
\cline { 2 - 8 } & Unidade & 2008 & 2009 & 2010 & 2011 & Tipo A & Tipo B \\
\hline $\begin{array}{l}\text { Coliformes } \\
\text { termotolerante }\end{array}$ & $\begin{array}{c}\text { NMP/g de } \\
\text { ST }\end{array}$ & $2.115 .583,0$ & $907.216,0$ & 644,0 & $19.709 .396,0$ & $<10^{3}$ & $<10^{6}$ \\
\hline $\begin{array}{l}\text { Ovos viáveis } \\
\text { de helmintos }\end{array}$ & $\begin{array}{c}\text { Ovos/g } \\
\text { ST }\end{array}$ & 19,0 & 6,2 & 22,0 & $<0,1$ & $<0,25$ & $<10$ \\
\hline Salmonella & $\begin{array}{c}\text { P/A em } \\
10 \mathrm{~g} \mathrm{de} \\
\text { MS }\end{array}$ & Ausente & Ausente & Presente & Presente & Ausência & Não há \\
\hline
\end{tabular}

Fonte: Próprios autores.

A Resolução CONAMA n 375/2006 estabelece duas classes de lodo, sendo elas tipo A e tipo B, as quais possuem diferentes parâmetros e exigências de qualidade microbiológica. Nesse sentido, as exigências para cada classe são: lodo tipo A coliformes termotolerantes $<10^{3} \mathrm{NMP} / \mathrm{g}$ de ST; ovos viáveis de helmintos $<0,25 \mathrm{ovo} / \mathrm{g}$ de ST; ausência de Salmonella em 10 g de ST e vírus < 0,25 UFP ou UFF/g de ST; lodo tipo B - coliformes termotolerantes $<10^{6} \mathrm{NMP} / \mathrm{g}$ de ST; ovos viáveis de helmintos < 10 ovos/g de ST (BRASIL, 2006).

Se fossem analisadas nesse composto orgânico, as exigências relativas ao lodo tipo A, nota-se através dos resultados, que mesmo não realizando a análise de vírus, todas as campanhas não atenderiam a Resolução CONAMA no 375/2006. Diante do exposto, o composto orgânico avaliado nesse trabalho, conforme Bastos et al. (2009) não pode ser utilizado em culturas de pastagens, olerícolas, tubérculos e raízes, bem como em culturas inundadas e em outras cuja parte comestível entre em contato com o solo.

Analisando individualmente cada parâmetro, 50\% dos resultados das análises de coliformes termotolerantes e ovos viáveis de helmintos estavam acima do limite para o 


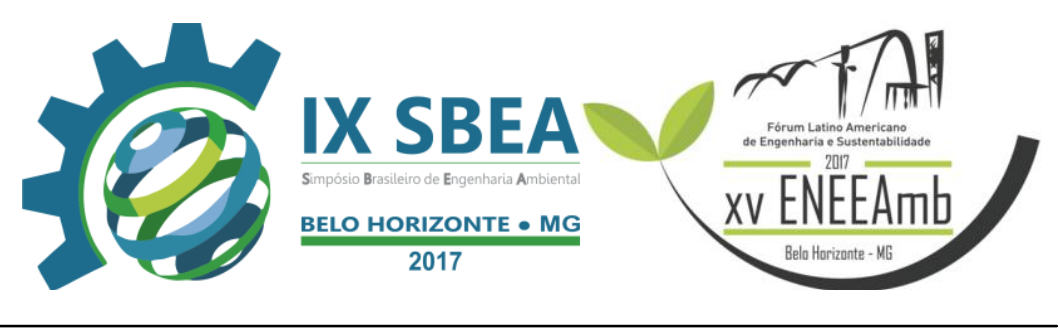

lodo tipo B. Diferentemente, Machado et al. (2013) ao caracterizar o lodo tipo B da ETE de uma indústria de laticínios em Guaratinguetá (SP) não encontrou parâmetros biológicos acima dos padrões da Resolução CONAMA n 375/2006.

Os resultados de coliformes termotolerantes oscilaram entre 644,0 a 19.709.391,0 NMP/g de ST, os de ovos viáveis de helmintos variaram entre <0,1 a 19,0 ovos/g de ST e os de Salmonella entre ausente e presente. A variação de patógenos no lodo está intimamente relacionada com o nível de saúde das pessoas atendidas pelo sistema de tratamento de esgoto, sendo que esse nível oscila ao longo do tempo (ANDREOLLI et al., 2014).

Além do mais, tendo em vista que os lodos das ETE's ou o composto orgânico não passa por nenhum processo de redução de patógenos e que o sistema de lodos ativados com aeração prolongada possui baixa capacidade de remoção de patógenos, qualquer variação na saúde da população atendida pelo sistema de tratamento refletirá na sanidade do composto orgânico aplicado no solo.

No que diz respeito à estabilidade (Tabela 3), apenas no ano de 2011 a análise realizada no composto orgânico apresentou-se como não estável. Para fins de utilização agrícola, o lodo ou produto derivado será considerado não estável se a relação entre sólidos voláteis e sólidos totais for igual ou superior 0,70 (BRASIL, 2006).

Tabela 3 - Resultados analíticos de estabilidade do composto.

\begin{tabular}{|l|c|c|c|c|c|}
\hline \multirow{2}{*}{ Parâmetro } & \multicolumn{4}{|c|}{ Resultados analíticos (\% p/p) } & Máximo \\
\cline { 2 - 5 } & 2008 & 2009 & 2010 & 2011 & 375 \\
\hline Sólidos totais & 75,10 & 14,20 & 20,20 & 20,40 & - \\
\hline Sólidos voláteis & 15,00 & 6,37 & 13,80 & 19,50 & - \\
\hline Estabilidade & Estável & Estável & Estável & Não estável & Estável \\
\hline
\end{tabular}

Fonte: Próprios autores.

As ETE's utilizadas na unidade de Montes Claros e de Teófilo Otoni são compostos por sistema biológico aeróbio de tratamento por lodos ativados em fluxo contínuo, com aeração prolongada. Segundo Von Sperling (2016), além da remoção da matéria orgânica e nitrogenada, um dos objetivos da etapa biológica é a estabilização do 


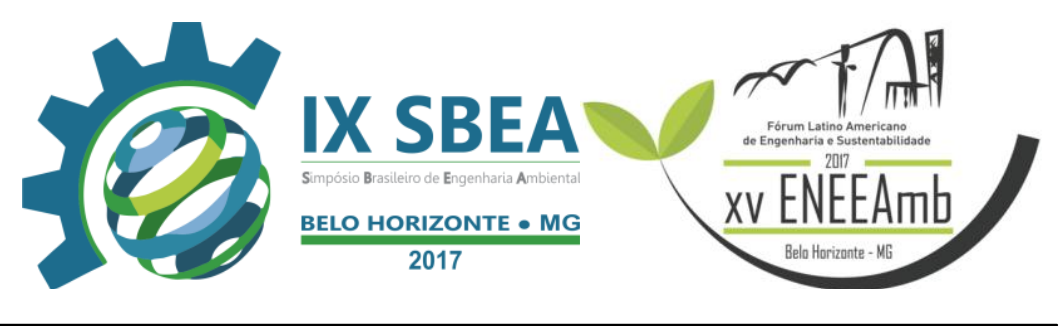

lodo no próprio reator. Diante disso, os lodos descartados nas ETE's deveriam estar estabilizados, no entanto, isso não ocorreu em função da retirada antecipada do lodo, sem observar a idade mínima para sua estabilização.

Através da análise dos resultados e estudo do sistema de tratamento adotado nas indústrias, é possível que o lodo não esteja estabilizado em virtude da variação na operação das ETE's. Por esse motivo, pode-se obter um composto orgânico estabilizado através da adoção de medidas tais como aumento da idade do lodo descartado, incremento da eficiência do sistema de aeração, entre outras.

Ao realizar uma pesquisa na literatura nacional, nota-se que a maioria dos trabalhos científicos desenvolvidos, estão, sobretudo, relacionados às caracterizações de lodos provenientes de estações de tratamento de concessionárias de saneamento. Há uma defasagem muito grande em pesquisas em lodos de ETE's industriais, e quando estas são realizadas tem-se uma preocupação maior com a análise de metais pesados e potencial fertilizante desse lodo.

A estabilidade do lodo aplicado em solo agrícola é tão importante quanto à presença de metais pesados e nutrientes desse resíduo, uma vez que a utilização de lodo não estabilizado é vetada pela Resolução CONAMA 375/2006. Comenta Adreolli et al. (2014) que a estabilização do lodo facilita a sua disposição final, abrindo alternativas para seu reuso como fertilizante e condicionador do solo. Além disso, o lodo não estabilizado pode gerar odores fétidos e atrair insetos, em virtude de ser um resíduo muito putrescível (VON SPERLING, 2014).

Das referências utilizadas no presente estudo, não foi encontrado autores que avaliaram a estabilidade do lodo para possibilitar as comparações, entretanto, talvez com uma pesquisa mais abrangente, inclusive em literaturas estrangeiras, pode-se encontrar temas específicos sobre a estabilidade de lodos de ETE's industriais

\section{CONCLUSÕES/RECOMENDAÇÕES}

Pode-se concluir que o composto orgânico avaliado não possui restrições quanto às substâncias inorgânicas, contudo, não atende os requisitos microbiológicos e de estabilidade fixados na Resolução CONAMA n 375/2006. 


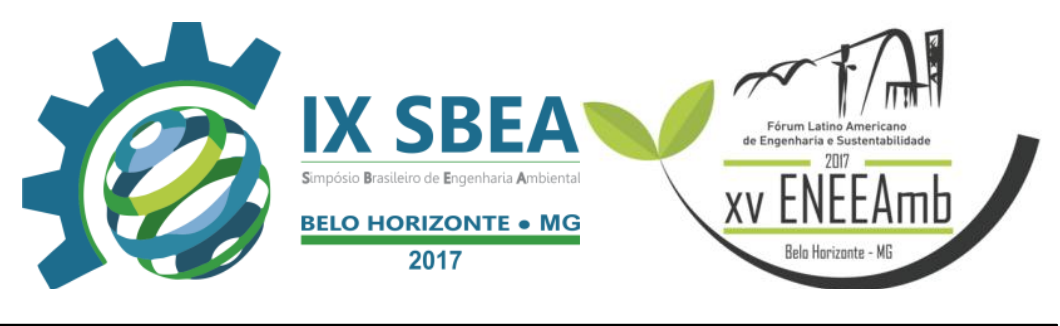

No que se refere aos requisitos microbiológicos, como solução imediata, seria a instalação de um sistema específico para o tratamento do esgoto doméstico e sanitário ou a implementação de etapas que promovam o tratamento do lodo, objetivando a redução dos patógenos.

Deve-se também ser observada a idade mínima para remoção dos lodos nas ETE's, possibilitando a sua estabilização nos próprios reatores. Na situação em que, independente do tempo de detenção, os lodos continuarem não estabilizados, é necessário o emprego de processos que permitam a sua estabilização, tais como a compostagem e secagem térmica.

\section{REFERÊNCIAS BIBLIOGRÁFICAS}

ANDREOLI, C.V.; VON SPERLING, M.; FERNANDES, F. Lodo de esgotos: tratamento e disposição final. $2^{\mathrm{a}}$ ed. Belo Horizonte: Editora UFMG, 2014. 444 p.

ASSOCIAÇÃO BRASILEIRA DE NORMAS TÉCNICAS. NBR-10007: Amostragem de resíduos. Rio de Janeiro, 2004. 21p.

BASTOS, R.K.X.; BEVILACQUE, P.D.; DIAS, G.M.F.; BARONY, F.J.A. Análise critica da legislação brasileira para o uso agrícola de lodos de esgotos na perspectiva da avaliação quantitativa de risco microbiológico. Revista AIDIS, Cidade do México, v.2, n.1, p. 143-159, 2009.

BEHLING, M.; DIAS, F.C.; AMARAL SOBRINHO, N.M.B.; OLIVEIRA. C.; MAZUR, N. Nodulação, acúmulo de nitrogênio no solo e na planta, e produtividade de soja em solo tratado com lodo de estação de tratamento de resíduos industriais. Bragantia, Campinas, v.68, n.2, p. 453-462, 2009.

BETTIOL, W.; CAMARGO, O.A. A disposição do lodo de esgoto em solo agrícola. In.: BETTIOL, W.; CAMARGO, O.A. (Coord.). Lodo de esgoto: impactos ambientais na agricultura. Jaguariúna: Embrapa Meio Ambiente, 2006. P.25-36.

BRASIL. Conselho Nacional do Meio Ambiente. Resolução no 375 de 29 de agosto de 2006. Define critérios e procedimentos, para o uso agrícola de lodos de esgoto gerados em estações de tratamento de esgoto sanitário e seus produtos derivados, e dá outras providências. Diário Oficial da União, Brasília, 30 ago. 2006. Disponível em: <http://www.siam.mg.gov.br/sla/download.pdf?idNorma=5956>. Acesso em: $22 \mathrm{de}$ maio de 2017.

LOPES, J.C.; RIBEIRO, L.G.; ARAÚJO, M.G.; BERALDO, M.R.B.S. Produção de alface com doses de lodo de esgoto. Horticultura Brasileira, Brasília, v.23, n.1, p. 143-147, 2005.

MACHADO, L.R.D.; TRANNIN, I.C.B.; MANCINI, S.D. Potencial agronômico de um lodo de esgoto industrial em atendimento a Resolução CONAMA no 375/2006. In: 


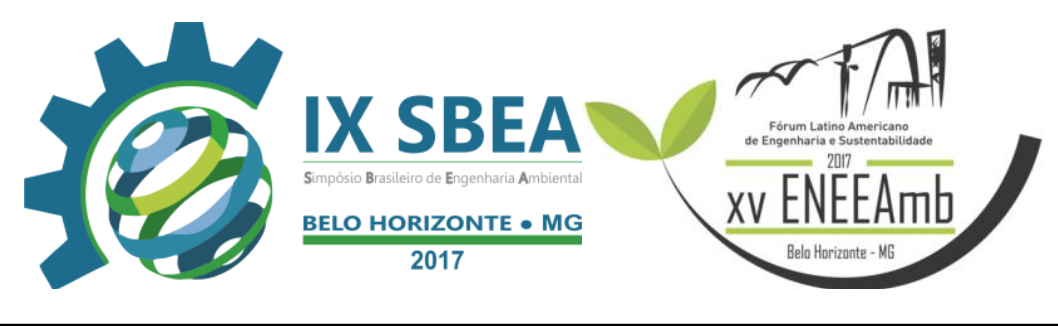

CONGRESSO BRASILEIRO DE GESTÃO AMBIENTAL E SUSTENTABILIDADE, 1., João Pessoa. Anais eletrônicos..., Congestas, 2013.

MAIA, L.C.; BELOTTI, F.M. Metais pesados em lodo de esgoto da ETE Laboreaux (Itabira/MG): quantificação total e restrições ao uso na fertilização de solos em área agrícolas. In: CONGRESSO INTERNACIONAL RESAG, 2., Aracajú. Anais eletrônicos... São Paulo, RESAG, 2015.

MARQUES, M.O.; NOGUEIRA, T.A.R.;. FONSECA, I.M.; MARQUES, T.A. Teores de $\mathrm{Cr}, \mathrm{Ni}, \mathrm{Pb}$ e $\mathrm{Zn}$ em Argissolo vermelho tratado com lodo de esgoto e cultivado com cana-de-açúcar. Bioterra, São Cristóvão, v.7, n.1, p. 133-143, 2007.

PAGORINI, E.S.; ANDREOLI, C.V. Introdução. In. ANDREOLI, C.V. (Coord.) Alternativas de uso de resíduos do saneamento. Rio de Janeiro: ABES, 2006. P. 1-6.

RIBEIRO, L.M.; SCHNEIDER, L.; SANCHES FILHO, P.J.; BOHM, G.B. Caracterização do lodo proveniente do reator anaeróbio de leito fluidizado, localizado no município de Pelotas / RS. Revista Thema, Pelotas, v.9, n.1, p. 1-2, 2012.

RIGO, M.M.; RAMOS, R.R.; CERQUEIRA, A.A.; SOUZA, P.S.A.; MARQUES, M. R.C. Destinação e reuso na agricultura do lodo de esgoto derivado do tratamento de águas residuária domésticas no Brasil. Gaia Scientia, João Pessoa, v.8, n.1, p. 174-186, 2014.

ROSA, E.V.C. Reaproveitamento de lodo têxtil em solo florestal: estudos dos aspectos físico-químicos, agronômicos e ecotoxicológicos. Florianópolis, 126 p., 2004. Tese (Pós-Graduação em Química) - Universidade Federal de Santa Catarina.

TRANNIN, I.C.B.; SIQUEIRA, J.O.; MOREIRA, F.M.S. Atributos químicos e físicos de um solo tratado com biossólido industrial e cultivado com milho. Revista Brasileira de Engenharia Agrícola e Ambiental, Campina Grande, v.12, n.3, p. 223-230, 2008.

VIEIRA, T.A. Implicações da disposição de lodos de estações de tratamento de esgoto em solo no Brasil. Rio Claro, 44 p., 2015. Monografia (Engenharia Ambiental) Universidade Estadual Paulista.

VON SPERLING, M. Introdução à qualidade das águas e ao tratamento de esgotos. $3^{\mathrm{a}}$ ed. Belo Horizonte: Editora UFMG, 2014. 452 p.

VON SPERLING, M. Lodos ativados. 4ª ed. Belo Horizonte: Editora UFMG, 2016. $461 \mathrm{p}$. 